\title{
An Online Interactive Courseware for the Course of Textile Materials
}

\author{
https://doi.org/10.3991/ijet.v12.i09.7494 \\ Zhen Li \\ Anhui Vocational and Technical College, Hefei, China \\ han19523@126.com
}

\begin{abstract}
In the era of network information, interactive multimedia application technology develops rapidly, and is widely applied in teaching courseware. Online interactive courseware is simple, clear, vivid, visual, convenient, flexible and fast, which also greatly reforms the teaching methods and has become a way of educational informatization. Online interactive courseware has been applied in the course of textile materials. This paper mainly aims to design and construct the method of testing and evaluating the multimedia courseware of Textile Materials based on the multimedia courseware interaction technology in combination with the patented method and device of PPT file playing. By appropriately applying and analyzing the courseware of Textile Materials based on the interaction technology, the results demonstrate that "flip" in class can be basically realized, to realize individualized learning; students' learning attitude can be changed, and students can form independent learning ability; student-student communications via multiple channels and equal student-teacher interaction can be promoted; comments and reviews can be given on the teaching results, so that the desired teaching objectives can be achieved. These findings indicate that online interactive courseware can improve the teaching effect of textile materials course, and relevant conclusions can provide technical reference for the application of online interactive courseware.
\end{abstract}

Keywords-Interactive courseware, multimedia teaching, design, textile materials

\section{$1 \quad$ Introduction}

Reciprocal teaching is a teaching method aiming of improving students' abilities of reading, comprehension and self-learning, which, through further research and development, is also a teaching mode developing based on the theory of scaffolding teaching [1]. Reciprocal teaching is classified into face-to-face classroom reciprocal teaching and non-face-to-face online reciprocal teaching. Interactive multimedia courseware, for online reciprocal teaching, is a digital learning form specific to the knowledge points and teaching links of specific subject meticulously designed and developed with multimedia network as the carrier and based on images, text, animations, and tables as the materials. It is featured by abundant content, distinct theme, 
scenario and visualization [2]. The proper application of online interactive courseware in multimedia teaching has changed students' learning style, so that students can fully exert their subjective initiative to realize individualized learning, exploring learning, independent learning and interactive learning by means of scenario situation based on the courseware online. Online interactive courseware plays an important role in the education and teaching at college and university, and develops rapidly in the Internet era.

\section{State of the art}

With the rapid development of the computer technology and its application in teaching process, the reciprocal learning mode based on the Internet also has gradually become the mainstream in the field of education. Bidirectional interaction can be realized via the Internet, so that the Internet has become a unique potential educational media. Schwarz et al [3] applied reciprocal teaching in medical education, and constructed the Medical Faculties Network (MEFANET). The MEFANET mainly consists of a new set of tools for technology-enhanced learning (including Sandbox (works in progress), WikiLectures (collaborative content authoring), MoodleMEFANET (central learning management system), and Serious Games (virtual casuistics and interactive algorithms)). The latest development in MEFANET was designed for indexing metadata about simulation-based learning objects, which is an also known as electronic virtual patient or virtual clinical cases. The surveys of Stergioulas et al. [4] indicated that students found an interactive teaching platform was a helpful learning tool that helped them improve acute medical knowledge. XX's surveys indicated that economic communities based in scattered or remote rural areas, such as agriculture and maritime, were in bad need of both Internet access at remote geographical locations and interactive multimedia content delivering education system. It was reported in Japan that [5] students at the Medical Faculty of Masaryk University (MF MU) were offered the interactive learning opportunities to use the virtual patient (interactive algorithms, clinical scenarios), the standardized patient, skills training on patient models, simulators with an embedded computer model or videoconference streaming from operating theatres. So far, these teaching methods have become part of undergraduate teaching of medicine, dentistry and nursing. Jia Tingbo [6] et al via case study of design and development of online technology institute of Yunnan Open University, introduced a new mode of realizing distance network-based reciprocal teaching and management that combines active server page technology (ASP) and database technology with modern education technology, which can significantly improve the efficiency and quality of distance education.

However, most colleges and universities fail to update the online course contents timely, teachers and students seldom interact with each other, and students have poor independent learning ability [7]. Thus, many colleges and universities are exploring the application of the new courseware mode. For example, the School of Textile and Clothing of Nantong University applied network-based interactive courseware in experiment teaching of the course of textile and clothing, established an integrative 
multi-layer network experiment teaching system, and achieved good teaching effect [8]. On the whole, the application of online reciprocal teaching is faced with the following barriers. (1) Windows presentation foundation (WPF) is adopted for online reciprocal teaching, but the WPF is provided with no control for slide presentation, and slide file cannot be played under the WPF user interface framework. Thus, it cannot be applied in teaching. (2) The existing online reciprocal teaching platforms provide a few functions, the main activity of online reciprocal teaching is limited to release of course contents, network is taken as a carrier of information transfer only rather than an interactive teaching platform, and the objective existence and subjective needs of the learners are ignored.

To keep pace with the industry development, this paper is intended to design and construct the method of online interactive testing and evaluating the multimedia courseware of Textile and Clothing Materials. This is the first time that online reciprocal teaching is put forward in the course of Textile and Clothing Materials. For the online reciprocal teaching, the "interaction five-step model" teaching method aiming of "enlivening the learning process" was combined, online interactive courseware is adopted, and target slide files were imported to the locally installed WPF software and played with the player control, to realize the playing of slide files under the WPF frame.

\section{Theoretical construction}

\subsection{Interactive five-step structure model}

The five steps of the model are logical basis, performance objective, learning activity, evaluation and feedback. Although the model is simple, it, having integrated various research results of reciprocal learning, can help learners acquire knowledge efficiently. (1) Logical basis: The logical basis is to explain why learners should learn the imparted contents. Regardless of the teaching or training theme, learners need to know why they should take the course. (2) Performance objective: The performance objective is to inform learners of what objectives they are expected to reach, and explicitly tell them what they will have acquired via the course. (3) Learning activity: The learning activity refers to designing various learning activities helpful for learners to achieve the performance objective, which is of great importance to reciprocal teaching or training. (4) Evaluation: It is to evaluate learners' performance by inspecting what they have learned. Evaluation is not made on learners themselves, but on their performance. (5) Feedback: It is to give feedback based on the performance objective, to make learners know whether they have done the right thing. Thus, they can make correction if they are told that they have done wrong. This is the feedback link of the interactive five-step structure model. Please see Fig. 1 for the interactive five-step structure model. 


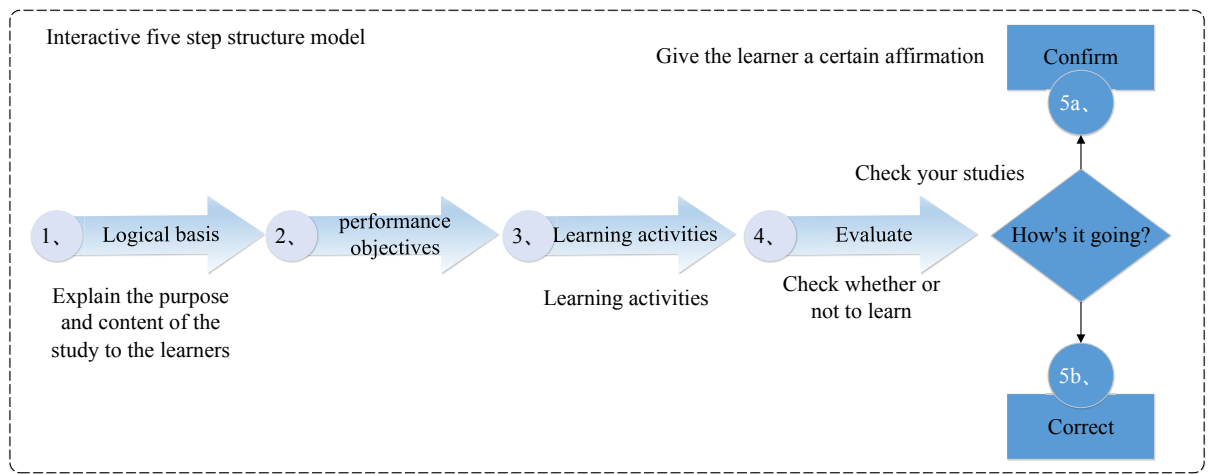

Fig. 1. Diagram of interactive five-step structure model

\subsection{Articulate Storyline2 technology}

For designing and developing the method of testing and evaluating multimedia courseware of Textile and Clothing Materials, the Articulate Storyline2 technology is adopted. Various question templates can be built in Storyline2, including 11 types of questions for scoring (the score and score deduction mechanism for giving a wrong answer can be set), 9 types of survey questions, and 5 types of free-answer questions (the object can be converted into interactive content that has the function of dynamic evaluating). The evaluation results will be displayed in the form of slide, covering test scores, test evaluation, and evaluation feedback. In the case that the built-in question templates of Storyline 2 are adopted for test and evaluation, only one question can be displayed in each slide. Thus, if you intend to raise a large number of questions, a large number of slides will be needed accordingly. Hence, most people elect to create a template with Storyline 2 tools for test and evaluation to organize the contents via variables and trigger action, so as to make up the defects of the built-in question templates of Storyline2. In other words, user can present multiple questions in one slide in this way.

The design flow is as shown below. As user inputs an answer of $\mathrm{F}$, the system assigns the value of the answer to txt_L1. If the answer is right, the system transfers it to $\mathrm{s} \_11=1$. Otherwise, the system assigns a value of 0 . Programming is not needed. Instead, it needs to trigger the conditions via the trigger in txt_L1 only. Fig. 2 shows flow chart of the test and evaluation design of Storyline 2 courseware. 


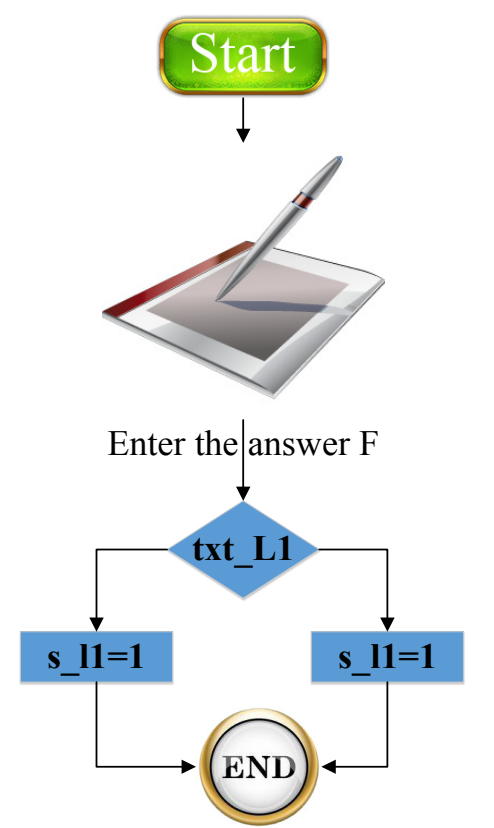

Fig. 2. Flow chart of the test and evaluation design of Storyline 2 courseware

The working principle of the trigger in txt_L1 is implemented via the following formula. $Q_{i j}$ refers to the probability density of correct answer of the variable $(\mathrm{i}, \mathrm{j})$ from the estimated operational process $r_{n i j}$ to $r_{s i j}$, qij refers to the probability density of correct answer achieved by the variable $(i, j)$ from the estimated operational process $r_{n i j}$ to $r_{s i j}$.

The quality of answer is subject to a threshold value. In the case the actual quality of answer is larger than the threshold value, the question can be ignored. Otherwise, the question must be answered. After applying the threshold value, the degree of accuracy of answers in progress can be adjusted, to obtain the final result Q.

$$
\begin{gathered}
a_{i j}=\frac{e-e^{q i j}}{r_{n i j}-r_{s i j}} \\
b_{i j}=\frac{e^{q i j} * t_{n i j}-e * t_{s i j}}{r_{n i j}-r_{s i j}} \\
Q_{i j}= \begin{cases}1 & \operatorname{In}\left(a_{i j} * t_{i j}+b_{i j}\right) \geq Q O \\
\operatorname{In}\left(a_{i j} * t_{i j}+b_{i j}\right) & \operatorname{In}\left(a_{i j} * t_{i j}+b_{i j}\right)<Q O\end{cases} \\
Q=\max Q_{k n}=\max \left(\prod_{(i, j) \in k n} Q_{i j}\right)
\end{gathered}
$$


After the trigger finishes work, another digital variable s_p1 will be created according to the following formula. The variable is for storing the total score record, namely the sum of scores of answers of all questions in the current slide.

$$
s_{-} p 1=\sum_{i=1}^{n} s_{-} l i
$$
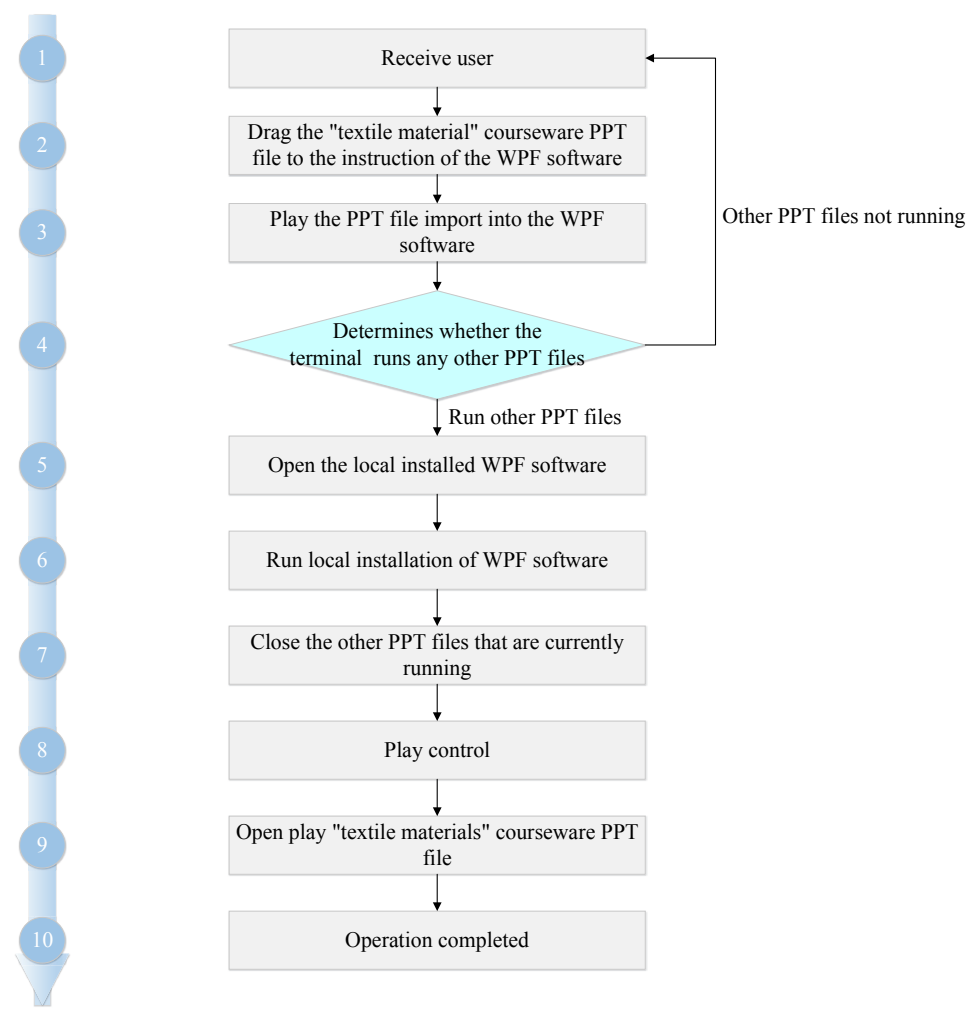

Fig. 3. Flow chart of the method of presenting slide file of courseware of Textile and Clothing Materials

The method and device technology of slide presentation is a new slide-type courseware presentation technology, of which the use steps are: install WPF software, start and run it, receive instruction (an operating command of user of dragging the target courseware into the WPF software), play the slide file of courseware with the player control. Thus, it can be regarded as an operating technology running under the WPF frame. Fig. 3 shows flow chart of the method of presenting slide file of courseware of Textile and Clothing Materials.

According to Fig. 3, through the design of test and evaluation in online reciprocal courseware and in combination with the method and device technology of slide file presentation of the course of Textile and Clothing Materials, feedback on the teaching effect can be given timely and the interactivity of online teaching can be fully aroused. 


\section{Design of online interactive courseware}

\subsection{Design of online interactive courseware}

Via the test and evaluation in the online interactive courseware of Textile and Clothing Materials, objects can be converted into interactive contents with dynamic evaluation function. The final evaluation results will be displayed in the form of slide, covering test scores, test evaluation and evaluation feedback. Test and evaluation are carried out in the form of test. Take the example of creation of self-defined questions, user can organize the contents via the variables and trigger action. For example, user intends to create self-defined questions of single choice. The user wants to create 10 questions of single choice about the course of Textile and Clothing Materials, and the right answer of each question should be chosen from four choices. 1 score will be obtained by choosing the right answer of each question, and 0 score will be obtained in the case of failure to choose the right answer. The concrete steps are: insert radio button by clicking "control" in the menu of the "insert" one by one, drag the buttons before each choice, define the name of the radio buttons to be rbn_s7A, rbn_s7B, rbn s7C, rbn s7D, and so on, pitch on the four buttons simultaneously with the aid of the Ctrl key, right-click at the time the mouse pointer turns into crosslet, pitch on the "button set" in the drop-down menu, click "new button set" in the secondary dropdown menu (to avoid giving the same button to different choices), and name the newly-created button set in the form of the question number (such as rbn_w7).

The next step is to create digital variables (such as s_s7, s_s8, s_s9 and s_s10) in the trigger, and put down the scores ( 1 score will be given if the right answer is chosen, and 0 score will be given in the case of failure to choose the right choice). For example, the right answer the seventh question is D choice. If rbn_s7D is clicked, 1 score will be given to s_s7; if rbn_s7A, rbn_s7B or rbn_s7C is clicked, 0 score will be given to s_s7.

The next step following triggering is to create a new digital variable s p2 (which is for storing the total scores of the 10 questions), click "next page" at the end of this page to calculate the sum of scores of all questions in the current slide, and save the sum in the digital variable s_p2.

$$
s_{-} p 2=\sum_{i=1}^{10} s_{-} s t
$$

Similarly, user can create self-defined questions of gap filling and true or false questions about the knowledge of Textile and Clothing Materials with the steps set forth above. Based on the test scores, evaluation and feedback can be given. If aggregate score is 20 , then evaluation can be carried out at four levels, namely 19-20, 15$18,11-14$ and $0-10$. Students' performance can be evaluated according to the given levels, and the evaluation result will be displayed via slide. Besides, the courseware can smartly push knowledge points according to the questions that students frequently give a wrong answer. Tab. 1 and Fig. 3 show the test results. 
Table 1. Test result

\begin{tabular}{cccc}
\hline Gap filling & Single choice & True or false question & Total score \\
\hline 5 & 6 & 4.5 & 15.5 \\
\hline
\end{tabular}

There are abundant question banks available in Storyline 2, so that user can rapidly generate a test by choosing questions of certain number from the question banks. Fig. 4 shows scene where students are taking a test via the online interactive multimedia teaching platform.

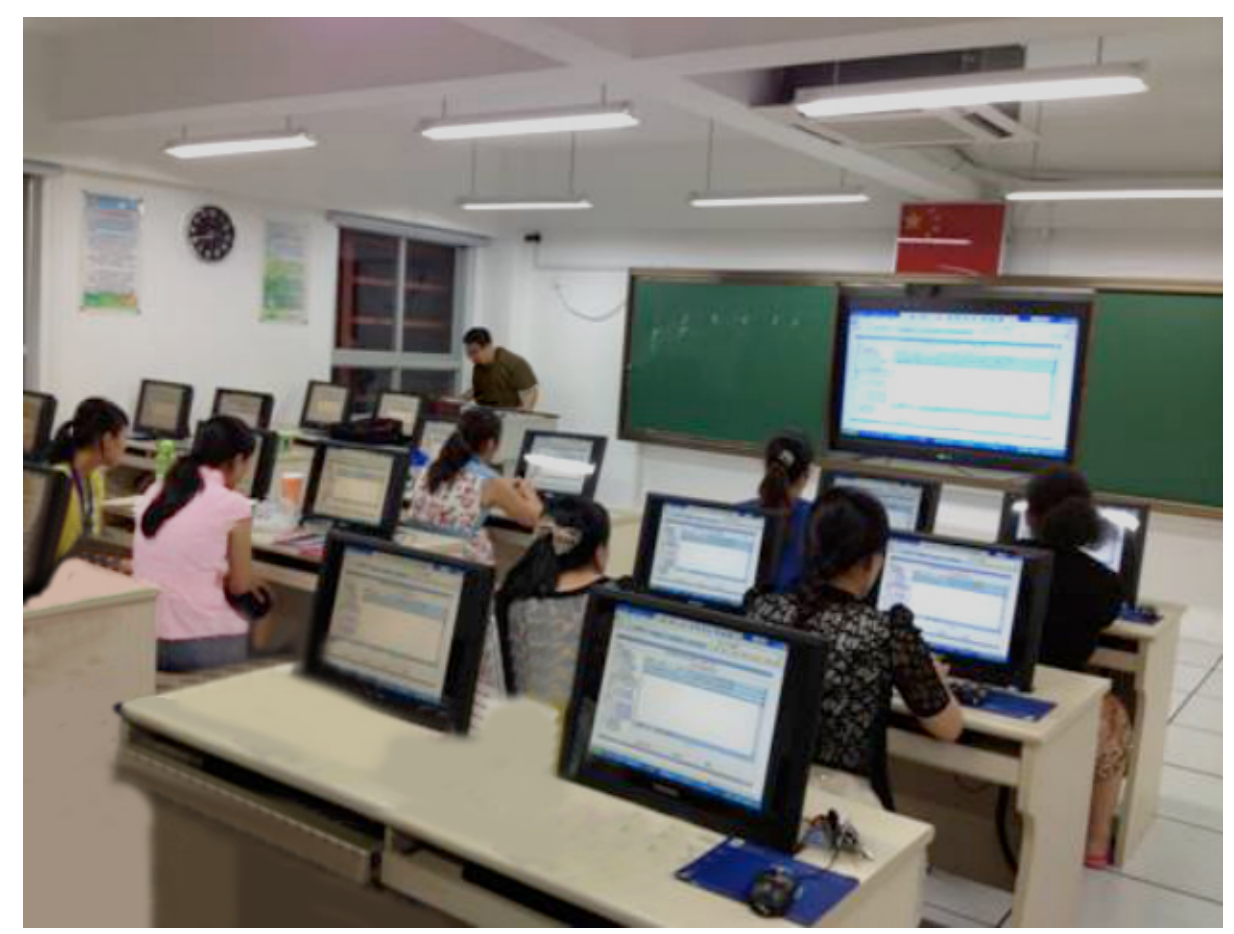

Fig. 4. Students are participating in online interactive multimedia teaching

After the steps set out above all are finished, the slide-format courseware can be presented. The procedure is as below: install WPF software, start and run it, accept the operating command from teacher of dragging the courseware of Textile and Clothing Materials into the WPF software, and play the slide file of the courseware of Textile and Clothing Materials via the player control. The device for playing slide file consists of 5 modules, the file playing module consists of 4 sub-modules, and the file playing sub-modules consist of a number of units. Fig. 5 shows picture of a classroom where online interactive multimedia teaching is implemented. 


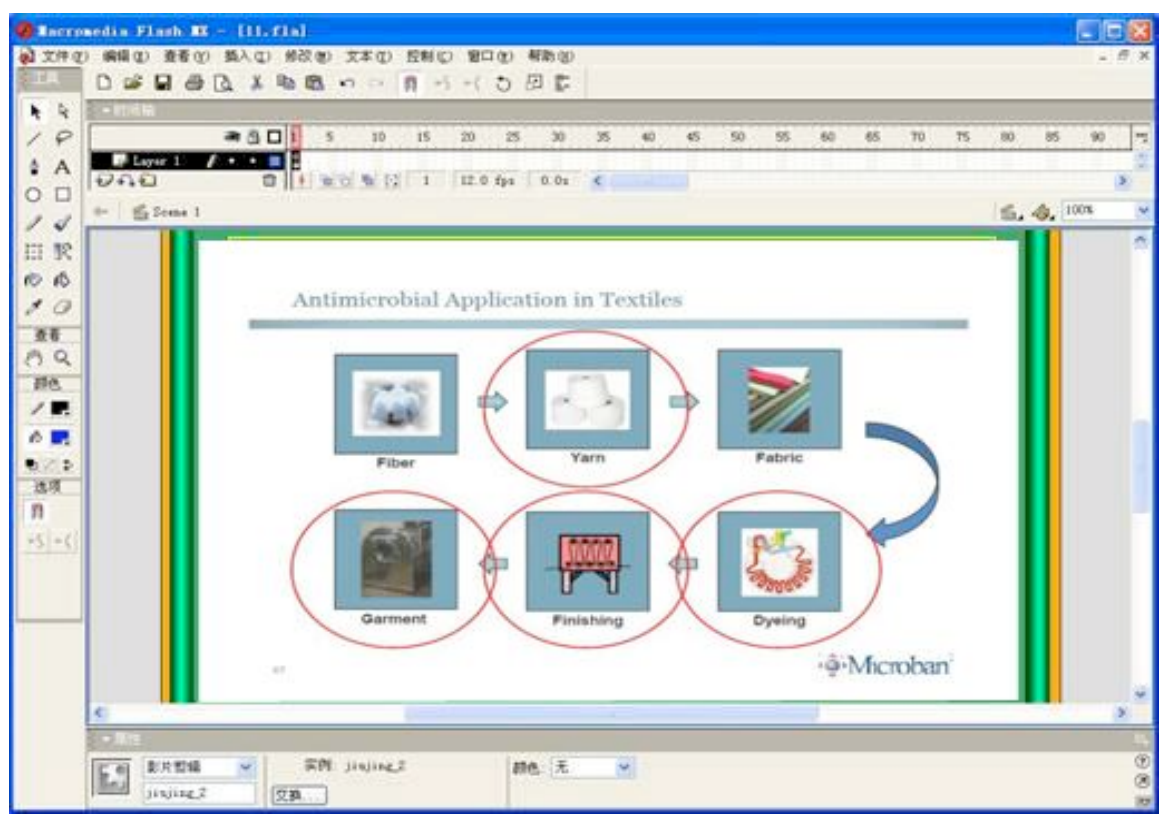

Fig. 5. Classroom of online interactive multimedia teaching

\section{$5 \quad$ Effect check}

For contrastive analysis of the design presented in this paper, an experiment was carried out. 70 students of Grade 2016 of the textile specialty of XX university were divided into two groups equally, an experimental group and a control group. The two groups are equally matched in academic performance, of which the average scores are 76. $68 \pm 10.33$ and 76. $48 \pm 10.98$ respectively $(\mathrm{P}=-0$. 516). There is no statistical difference, and the comparison of the two groups makes sense. For purpose of the experiment, the same teacher was assigned to teach the two groups, and the course of Textile and Clothing Materials was focused on. The experimental period is one semester. For the control group, the traditional teaching mode (classroom teaching) was implemented, in combination with students' independent study of online excellent courses, but no real-time online teaching interaction and interactive courseware was applied. For the experimental group, besides the teaching mode, teaching objectives, teaching contents, and key points and difficulties of the control group, an interaction link was added. The academic performance of all the students of Grade 2016 of the textile specialty was surveyed to check the application effect of the online interactive multimedia courseware of Textile and Clothing Materials. For the questionnaire on satisfaction with the teaching activity, the Likert 5 system was adopted (completely dissatisfied, dissatisfied, neutral, satisfied, greatly satisfied). For the survey, it was rated to be satisfied if the score is higher than 3. Lastly, the questionnaire was entered with Epidate3.02 software, and statistical description and independent sample $\mathrm{T}$ test were completed with SPSS18.0 software (level $\alpha=0.05$ ). 
Paper-An Online Interactive Courseware for the Course of Textile Materials

Table 2. The results of the teaching experiment

\begin{tabular}{|l|c|c|c|c|c|c|}
\hline \multicolumn{1}{|c|}{ Group } & $\begin{array}{c}\text { Theoret- } \\
\text { ical score } \\
\mathbf{( 1 0 0 )}\end{array}$ & $\begin{array}{c}\text { Experi- } \\
\text { ment score } \\
\mathbf{( 1 0 0 )}\end{array}$ & $\begin{array}{c}\text { Choice } \\
\text { question } \\
\mathbf{( 4 0 )}\end{array}$ & $\begin{array}{c}\text { Explanation } \\
\text { of nouns (10) }\end{array}$ & $\begin{array}{c}\text { Short an- } \\
\text { swer ques- } \\
\text { tion (30) }\end{array}$ & $\begin{array}{c}\text { Analytical } \\
\text { reasoning } \\
\text { question } \\
\mathbf{( 2 0 )}\end{array}$ \\
\hline Experimental Group & $87.2 \pm 5.25$ & $84.17+8.51$ & $33.38+2.09$ & $8.72+0.52$ & $26.16+1.57$ & $18.94+1.05$ \\
\hline Control Group & $82.7 \pm 5.76$ & $85.38+6.34$ & $33.07+2.3$ & $8.77+0.58$ & $25.31+1.73$ & $15.53+1.15$ \\
\hline $\mathrm{t}$ & 3.27 & -0.657 & 0.549 & -0.359 & 2.06 & 12.358 \\
\hline $\mathrm{P}$ & 0.002 & 0.513 & 0.585 & 0.721 & 0.043 & 0.000 \\
\hline
\end{tabular}

Tab. 2 shows the result of comparison between the two groups in theoretical score and experiment score. In respect of theoretical score, the experimental group are superior to the control group (experimental group: 87.20 \pm 5.25 ; control group: $82.69 \pm 5.76)$, of statistic difference $(\mathrm{P}=0.002)$. With respect to the score of choice question, the average score of the experimental group is 33.38 2.09 , and that of the control group is $33.07 \pm 2.30$, of no statistic difference $(\mathrm{P}=\mathrm{O} .585)$; with respect of the score of explanation of nouns, the average score of the experimental group is $8.72 \pm 0.52$, and that of the control group is $8.77 \pm 0.58$, of no statistic difference; with respect of the scores of short answer question and analytical reasoning question, the average scores of the experimental group are 26.16 \pm 1.57 and $18.94 \pm 1.05$, and that of the control group are $25.31 \pm 1.73$ and $15.53 \pm 1.15$, of statistic difference $(\mathrm{P}=0.043$, and 0.000 ). The results set out above indicate that the interactive multimedia courseware has a positive effect on the course of Textile and Clothing Materials, students are considerably satisfied with the courseware, and the courseware makes students take a positive learning attitude and enables students to study independently; students and teachers are provided with more channels for communication and interaction, so that teachers can timely feed back and evaluate the teaching results to get closer to the desired teaching objectives.

\section{Conclusions}

In this paper, the interactive multimedia courseware of Textile and Clothing Materials is designed and constructed in a new way based on multimedia interaction technology and in combination with the newly-developed interactive courseware. The textile specialty is a specialty integrating theory and practice. To keep pace with the development of the textile industry, professional skilled talents must be trained. Hence, sound education becomes greatly important. However, the knowledge and courses about the textile specialty offered by Chinese colleges and universities are imparted in a dull way, mainly with the traditional teaching method, which greatly hinders the development of the specialty. In this research, the resource shortage has been made up and maximization of sharing has been realized by designing, analyzing and applying the courseware of Textile and Clothing Materials based on the interaction technology; having increased communication platform to provide teachers and students with more channels for communication and interaction; and having moti- 
vated students to actively learn knowledge rather than passively accepting knowledge. Besides, a student-centered teaching mode has been built with the interactive five-step model, to help students independently explore, study, analyze and solve problems and acquire knowledge in learning process. Students are suggested to cooperate with each other, to realize real interactive learning. The result of teaching practice shows that students have achieved good results with the help of the courseware and are satisfied with the courseware. But it needs to be further perfected and improved. This courseware is helpful to improve the teaching efficiency, but online interactive also consumes time. To handle online reciprocal teaching, teachers are required to have a more extensive scope of knowledge, and be more experienced in and enthusiastic for teaching. Teachers also should try more teaching methods according to the actual teaching needs. All these need us to do more efforts.

\section{$7 \quad$ References}

[1] Chudaykina, G., Kostovarova, V. Excursion as one of the methods of interactive learning foreign languages in universities for tourism and service, 2015, vol. 9(2), pp. 100-106.

[2] Rezvanova, I.Y. The development of interactive education in the north caucasus: the experience of the international training and research laboratory, The World of Scientific Discoveries. 2015, vol. 63(3.8), pp. 3732-3749.

[3] Schwarz, D., Štourač, P., Komenda, M., et al. Interactive Algorithms for Teaching and Learning Acute Medicine in the Network of Medical Faculties MEFANET. Journal of Medical Internet Research, 2013, vol. 15(7), pp. e135. https://doi.org/10.2196/jmir.2590

[4] Serif, T., El-Haddadeh, R., Stergioulas, L., et al. Satellite-enabled Interactive Education: An Evaluation of Satellite-based Distance Learning Architectures and Network Interoperability Issues. IET Seminar on Digital Video Broadcasting over Satellite: Present and Future, 2006, pp. 75-80.

[5] Harazim, H., Štourač, P., Kosinová, M., et al. Use of interactive education in undergraduate teaching of acute medicine: The virtual and standardised patient, operating theatre broadcasting. Anesteziologie A Intenzivni Medicina, 2015, vol. 26(4), pp. 202-212.

[6] Jia, T.B., Luo, J., Zhou, X.J., et al. A Web-based Interactive Instruction and Management System Developed on SP and Database Technologies. Distance Education in China, 2001, vol. 21(4), pp. 58-60.

[7] Du, X.J. Research on teaching method based on interactive learning. Journal of Educational Institute of Jilin Province, 2015, vol. 31(4), pp. 77-80.

[8] Ye, L. Reform and practice of interactive layering teaching in fashion major. Shandong Textile Economy, 2015, vol. 32(12), pp. 67-68.

\section{Author}

Zhen Li is a lecturer in the Anhui Vocational and Technical College, Hefei 230011, China(han19523@126.com).

Article submitted 25 April 2017. Published as resubmitted by the author 24 July 2017. 